\title{
A piezoelectric microvalve for cryogenic applications
}

\author{
Jong M Park ${ }^{1}$, Ryan P Taylor ${ }^{2}$, Allan T Evans ${ }^{1}$, Tyler R Brosten ${ }^{2}$, \\ Gregory F Nellis ${ }^{2}$, Sanford A Klein ${ }^{2}$, Jeffrey R Feller ${ }^{3}$, Louis Salerno ${ }^{3}$ \\ and Yogesh B Gianchandani ${ }^{1}$ \\ ${ }^{1}$ Department of Electrical Engineering and Computer Science, University of Michigan, Ann Arbor, \\ 1301 Beal Ave., Ann Arbor, MI 48109, USA \\ ${ }^{2}$ Department of Mechanical Engineering, University of Wisconsin, Madison, 1500 Engineering Dr., \\ Madison, WI 53706, USA \\ ${ }^{3}$ NASA Ames Research Center, Moffett Field, CA 94035, USA \\ E-mail: parkjong@umich.edu
}

Received 23 August 2007, in final form 9 November 2007

Published 11 December 2007

Online at stacks.iop.org/JMM/18/015023

\begin{abstract}
This paper reports on a normally open piezoelectrically actuated microvalve for high flow modulation at cryogenic temperatures. One application envisioned is to control the flow of a cryogen for distributed cooling with a high degree of temperature stability and a small thermal gradient. The valve consists of a micromachined die fabricated from a silicon-on-insulator wafer, a glass wafer, a commercially available piezoelectric stack actuator and Macor ${ }^{\mathrm{TM}}$ ceramic encapsulation that has overall dimensions of $1 \times 1 \times 1 \mathrm{~cm}^{3}$. A perimeter augmentation scheme for the valve seat has been implemented to provide high flow modulation. In tests performed at room temperature the flow was modulated from $980 \mathrm{~mL} \mathrm{~min}^{-1}$ with the valve fully open $(0 \mathrm{~V})$, to $0 \mathrm{~mL} \mathrm{~min}^{-1}$ with a $60 \mathrm{~V}$ actuation voltage, at an inlet gauge pressure of $55 \mathrm{kPa}$. This range is orders of magnitude higher flow than the modulation capability of similarly sized piezoelectric microvalves. At the cryogenic temperature of $80 \mathrm{~K}$, the valve successfully modulated gas flow from $350 \mathrm{~mL} \mathrm{~min}^{-1}$ down to $20 \mathrm{~mL} \mathrm{~min}^{-1}$ with an inlet pressure of $104 \mathrm{kPa}$ higher than the atmosphere. The operation of this valve has been validated at elevated temperatures as well, up to $380 \mathrm{~K}$. The valve has a response time of less than $1 \mathrm{~ms}$ and has operational bandwidth up to $820 \mathrm{kHz}$.
\end{abstract}

(Some figures in this article are in colour only in the electronic version)

\section{Introduction}

Future space missions will require cooling of large optical structures and cryogenic storage systems with a high degree of temperature stability and a small temperature gradient $[1,2]$. It is challenging to provide strict thermal stability to these large structures with a single cryocooler. An attractive solution is to implement a distributed network of elements that provide appropriate cooling for the system. More specifically, multiple cooling elements, each consisting of actively controlled valves, integrated heat exchangers and temperature sensors, will be positioned across the structure to be cooled. The actively controlled valves are capable of regulating the flow of refrigerant in response to local temperature. With each cooling element working independently in response to local sensors, temperature can be controlled efficiently. In order to realize such a distributed cooling system, it is essential to have valves that work reliably at cryogenic temperatures and can provide a large flow modulation capability. Due to the intended operation in a space environment as a part of the cryogenic cooling system, the active microvalve must have a wide range of operating temperature, remaining functional at cryogenic temperatures during operation and at ambient and even slightly elevated temperature for qualification testing and contamination control processes. The valve must provide a high degree of flow modulation for adequate cooling. Since excess cooling is tolerable, a normally open valve is desirable; the open state 
is a safe failure mode that does not block refrigerant flow. Finally, for some applications it is desirable that the valve be able to withstand a large pressure difference so that it can accomplish the free expansion in a Joule-Thompson cooling cycle.

Several actuation schemes were considered to meet these demands. One of the first active micromachined valves reported in the literature, which uses electromagnetic actuation, consists of an etched silicon orifice, a nickel diaphragm, and a solenoid actuator and plunger assembly [3]. The main advantage of magnetic actuation is the ability to create a relatively large force and large deflections with a low driving voltage. However, magnetic actuation tends to require significant power for operation, up to several watts [4-6]. Electrostatic actuation is characterized by a fast response and low power consumption; however, the force is relatively small, limiting its applications to low inlet pressures. Furthermore, arrays of valves are needed for flow control, because electrostatically driven valves are typically operated in a binary mode rather than as proportional valves [7-9]. A pressure-balancing scheme has been explored for high pressure applications, but abrupt turn-on behavior is inevitable [10]. Various forms of thermal actuation schemes such as thermopneumatic [11, 12], bimetallic [13-15] and shape memory alloy [16] take advantage of thermal properties of materials to generate displacements. These actuation schemes generally produce considerable force while simultaneously achieving relatively large displacements. However, these have relatively high power consumption and slow response times. In addition, their performance may be degraded when operated at cryogenic temperatures.

For this work, piezoelectric actuation was chosen because it allows proportional flow control and is capable of generating high force with low power consumption. Out-of-plane, stacked PZT (lead zirconate titanate) actuation has been widely used in valves. One of the earliest works on fabrication of a piezoelectric microvalve was presented by Esashi et al [17-19]. The valve is constructed from silicon mesa suspended with a flexible silicon diaphragm pressed against a glass plate or a polymer membrane by a stack piezoelectric actuator. While piezoelectric microvalves have been developed for space applications [20, 21], these were not designed for cryogenic operation and for high flow modulation. A major disadvantage of piezoelectric actuation is its small stroke, even for large voltages. At cryogenic temperatures, the displacement is further reduced due to degradation of the piezoelectric coefficient. This drawback can be potentially overcome by hydraulic amplification; however, fabrication of such devices is often complicated $[22,23]$. In this effort, the flow limitation imposed by the small displacement is addressed by perimeter augmentation of the valve seat. A ceramic casing is utilized to reduce the thermal mismatch between the packaging material and the PZT actuator, and the actuator is pre-stressed during assembly to provide a normally open valve. The development, modeling and test results of piezoelectric valves fabricated from $\mathrm{Si}$, glass and ceramic are presented. The valves are evaluated at low temperature, as well as in a high pressure environment ${ }^{4}$.

4 Portions of this work were published in conference abstract form in [24].

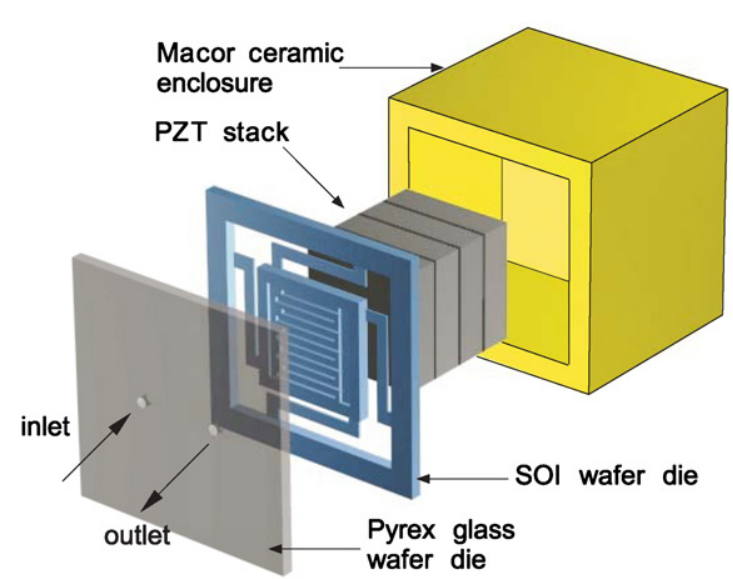

Figure 1. Microvalve concepts: the valve consists of a ceramic-PZT-Si-glass structure. A PZT stack actuator moves the silicon plate to open or close the valve. Micro-groove patterns are fabricated on the silicon plate to increase the flow area.

The device structure and operation are described in section 2. The fabrication and assembly process is discussed in section 3. Experimental results compared with modeling data are presented in section 4 , followed by discussion and conclusion in section 5 .

\section{Device structure and operation}

The valve operates by pushing a bulk Si micromachined plate against a Corning \#7740 Pyrex glass substrate that has the inlet and outlet holes in it (figure 1). A commercially available multilayered PZT stack is used to drive the silicon valve plate (Physik Instrumente, Germany, PL055). The PZT stack has a footprint of $5 \times 5 \mathrm{~mm}^{2}$ and a height of $6 \mathrm{~mm}$. In order to operate over a wide range of operating temperature, it is necessary to carefully select the materials so that temperature expansion mismatches do not inhibit operation of the device. $\mathrm{Macor}^{\mathrm{TM}}$, a glass mica ceramic, is used as the primary packaging material. It can be easily machined with precision and has a thermal expansion coefficient of $7.4 \mathrm{ppm} \mathrm{K}^{-1}$. In addition, it has zero porosity, does not outgas in vacuum environment and can be used with epoxy to provide a hermetic seal. The ceramic enclosure measures $1 \times 1 \times 1 \mathrm{~cm}^{3}$, and has a $6 \mathrm{~mm}$ deep cavity with $1 \mathrm{~mm}$ thick walls on all four sides.

The piezoelectric coefficient of PZT is reduced at cryogenic temperatures because the process of domain wall movement in the PZT becomes more difficult as the temperature is lowered, which results in stiffer material [25]. To quantify the cryogenic performance of PZT, a series of experiments were conducted to measure the properties of PZT at various temperatures. A special test apparatus was built so that the experiment could be carried out in a vacuum chamber. An actively cooled radiation shield and additional multiple layer insulations were used to minimize the radiation heat leak. A Cryomech AL60 GM cryocooler was used to cool the sample down to $40 \mathrm{~K}$ and then the test platform was allowed to warm up in a controlled manner using an installed heater. During the warm up, the PZT actuator displacement measurements were 


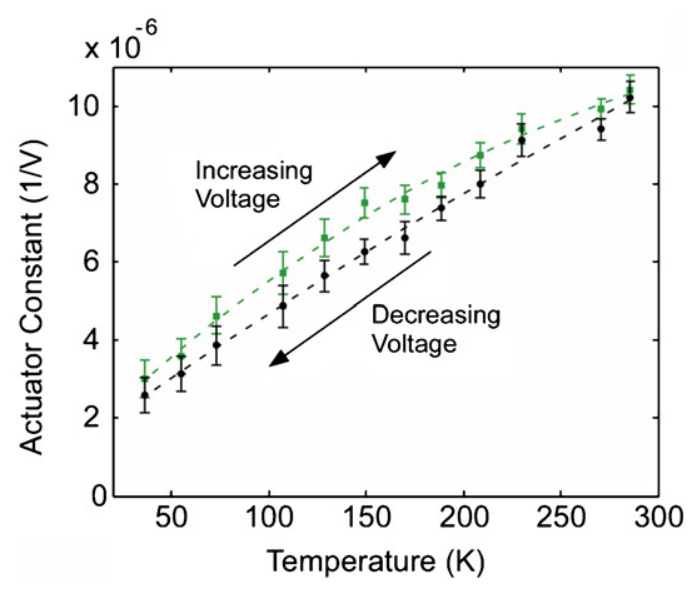

Figure 2. Measured PZT stack actuation constant (strain per unit voltage) as a function of temperature. The data are separated into two categories related to the increasing and decreasing voltages. As the operating temperature is reduced, the actuator constant decreases.

taken at various temperatures using two fiber-optic probes. More details about the experiments can be found in [26]. For convenience, an actuator constant for this particular PZT is defined as strain per unit voltage, and this actuator constant at various temperatures is presented in figure 2. Note that the actuator displacement gradually reduces as the temperature decreases; at $40 \mathrm{~K}$, it is approximately one third of the room temperature value.

The degraded performance of PZT at cryogenic temperatures poses another design challenge for this microvalve in providing sufficient flow rate. The following simple calculation provides an estimate of the flow that is required to provide adequate cooling. Assume that a potential application requires that $1.0 \mathrm{~W}$ of cooling load $(\dot{q})$ be accepted by a flow of helium that is at a nominal pressure $\left(P_{\text {nom }}\right)$ of 1.0 $\mathrm{MPa}$ and temperature $\left(T_{\mathrm{nom}}\right)$ of $25 \mathrm{~K}$. The temperature rise $(\Delta T)$ specifies the mass flow rate that is required $(\dot{m})$ according to an energy balance:

$$
\dot{q}=\dot{m} c_{\mathrm{p}} \Delta T
$$

where $c_{\mathrm{p}}$ is the nominal constant pressure specific heat capacity. For a $1.0 \mathrm{~W}$ load with a $0.1 \mathrm{~K}$ temperature rise, the required mass flow rate is $1.8 \mathrm{~g} \mathrm{~s}^{-1}$. The pressure drop $(\Delta P)$ coupled with the mass flow rate specifies the nominal valve flow area $\left(A_{\text {valve }}\right)$ which is illustrated in equation (2).

$$
\Delta P=C_{\mathrm{D}} \frac{\dot{m}^{2}}{2 \rho A_{\text {valve }}^{2}}
$$

where $\rho$ is the nominal density and $C_{\mathrm{D}}$ is a nominal discharge coefficient that is close to unity [27]. If the pressure drop is assumed to be kept at $10 \mathrm{kPa}$ to avoid excessively burdening the fluid circulation system then equation (2) illustrates that a valve flow area of $3.0 \times 10^{-6} \mathrm{~m}^{2}$ is required. In this case, the flow area is given by the product of valve seat perimeter surrounding inlet or outlet hole $(p)$ and the separation between the silicon valve plate and glass seat $(\delta)$.

$$
A_{\text {valve }}=\delta \cdot p \text {. }
$$

The required flow area is quite large considering that the PZT actuator can provide at most $6 \mu \mathrm{m}$ displacement at room temperature, and even less at lower temperatures. To achieve this large flow area, the perimeter of the valve seat is substantially increased by implementing serpentine groove patterns on the silicon valve plate $\left(5 \times 5 \mathrm{~mm}^{2}\right)$, as shown schematically in figures 1 and 3 . Each groove is $50 \mu \mathrm{m}$ wide and $120 \mu \mathrm{m}$ deep and the perimeter measures about $127 \mathrm{~mm}$, capable of providing much larger flow.

The silicon valve plate is suspended by four flexures in crab-leg formation; each measures $500 \mu \mathrm{m}$ wide, $4200 \mu \mathrm{m}$ long and $50 \mu \mathrm{m}$ thick. These flexures are flexible enough to move freely upon the actuation of PZT (spring constant $\approx 500 \mathrm{~N} \mathrm{~m}^{-1}$ ) but are rigid enough to hold the plate in place. In addition, the crab-leg formation can relieve any stress that is caused by the large temperature variation. This characteristic was verified by finite element analysis of the structure. Assuming that the anodic bonding between the silicon and glass was done at $400{ }^{\circ} \mathrm{C}$, at room temperature, the maximum stress of $21 \mathrm{MPa}$ was observed at the corners of bonding rim but the stress on the flexure and silicon valve plate was negligible.

The bonded die, PZT actuator and ceramic enclosures are joined using Stycast epoxy, which provides exceptional stability in cryogenic conditions. The PZT actuator is not bonded to the Si plate, which helps to accommodate variations in height caused by the expansion mismatch between the PZT and the Macor.

\section{Device fabrication}

To ensure control of material properties, the final device consists of only bulk materials. Deposited thin films are not used for any structural layer, although they are used in intermediate steps. The fabrication process uses two wafers: a silicon-on-insulator (SOI) wafer which has a device layer, buried oxide layer and carrier wafer thicknesses of $50 \mu \mathrm{m}$, $0.5 \mu \mathrm{m}$ and $450 \mu \mathrm{m}$, respectively, and a $500 \mu \mathrm{m}$ thick Pyrex glass wafer. The fabrication processes for SOI and glass wafers are illustrated in figure 3, and the assembly with the PZT and the ceramic housing is illustrated in figure 4.

Deep reactive ion etching (DRIE) of silicon was used to form flexures, the valve plate and groove patterns in the plate. DRIE provides high etching speed, high aspect ratio capabilities and good selectivity. However, the uniformity of DRIE is not reliable across a full wafer [28, 29]. The buried oxide layer in SOI wafers provides an etch stop for DRIE, while the epitaxial layer provides a well-controlled flexure thickness, smooth surfaces and bulk Si properties. The first DRIE step etches down to the buried oxide layer from the top and defines the flexure structures. Then the bottom side is patterned with $\mathrm{Al}$ and photoresist. The photoresist acts as an etch mask for the second DRIE step that is approximately $400 \mu \mathrm{m}$ deep. Next, the photoresist is removed and $\mathrm{Al}$ is used as an etch mask for the final DRIE step which engraves serpentine grooves for perimeter augmentation. The Al layer is then removed and the wafer is prepared for bonding. A scanning electron microscope (SEM) image of a valve plate 


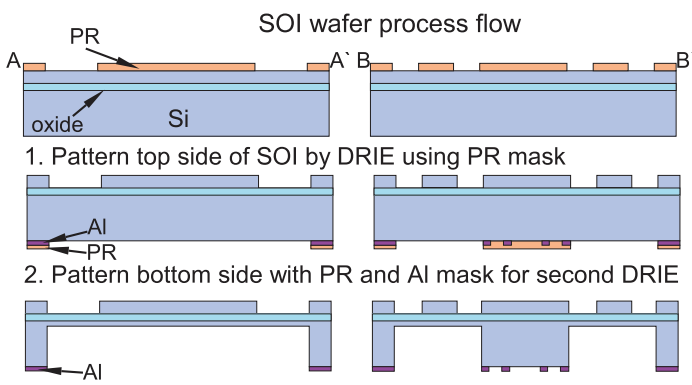

3. When almost finished, remove PR and continue DRIE for grooves using Al mask
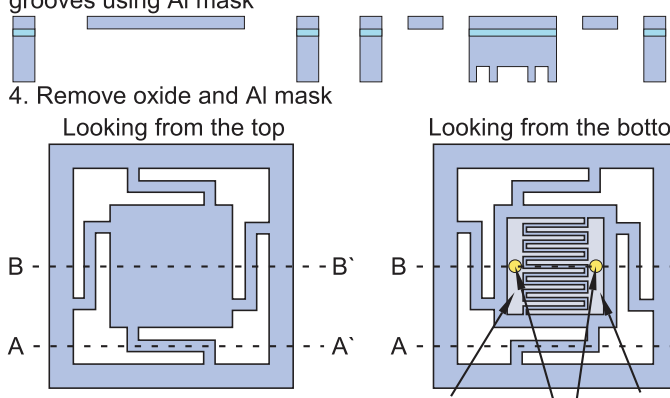

Looking from the bottom

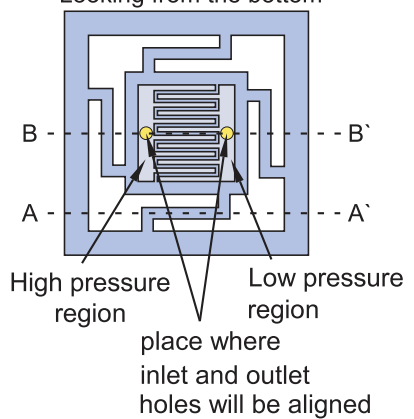

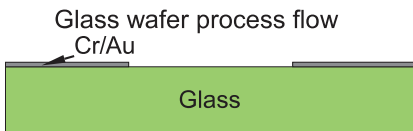

1. Form Cr/Au etch mask

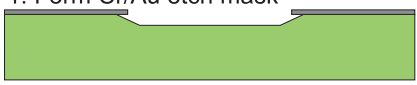

2. Wet etch glass in $\mathrm{HF}: \mathrm{HNO}_{3}$ solution

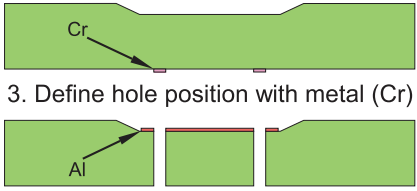

4. Create hole using ECDM process followed by Al deposition

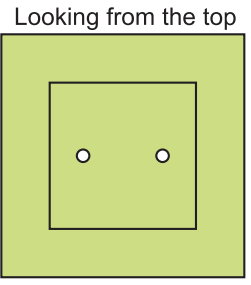

Figure 3. Si-glass micromachining process: the buried oxide layer in a SOI wafer acts as an etch stop for DRIE. A three-step DRIE process is illustrated for the SOI wafer. A glass wafer undergoes a wet etch process and electrochemical discharge machining (ECDM) for inlet and outlet hole creations. Finally, an Al metal layer is deposited and patterned in preparation for anodic bonding to prevent bonding of the valve seat to the glass substrate.

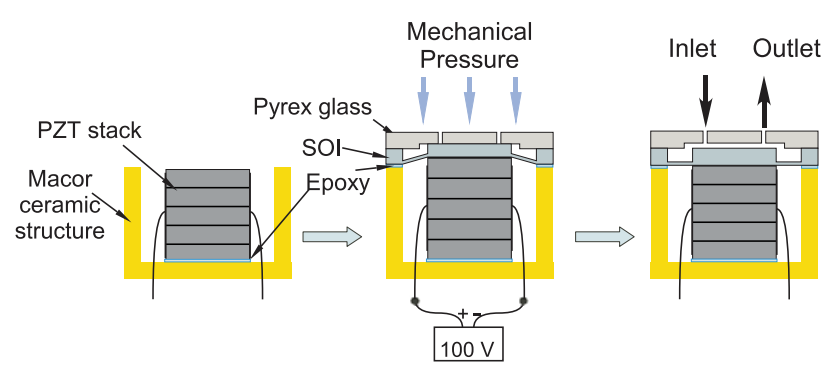

(a)

$(c)$
Figure 4. Pre-stressed microvalve assembly procedure: (a) first, a PZT stack is attached to the Macor ceramic structure using epoxy. (b) Then a Si-glass die is bonded at the end of PZT and Macor structure by an epoxy joint. During this procedure, the PZT stack is actuated until the epoxy is fully cured which results in a normally open valve $(c)$.

after these three-step DRIE is shown in figure 5(a). Each groove width is $50 \mu \mathrm{m}$ and they are etched approximately $120 \mu \mathrm{m}$ deep.

For the glass wafer, a recess of $2 \mu \mathrm{m}$ is made to accommodate the PZT displacement (figure 4). The recess is formed by wet etching the glass in $\mathrm{H}_{2} \mathrm{O}: \mathrm{HF}: \mathrm{HNO}_{3}=10: 7: 3$ solution, using $\mathrm{Cr} / \mathrm{Au} / \mathrm{PR}$ layer as an etch mask. After the recess formation, the etch mask is removed and a thin $\mathrm{Cr}$ layer $(100 \mathrm{~nm})$ is patterned to define the position of inlet and outlet holes that are formed using electrochemical discharge machining (ECDM) [30]. ECDM was chosen for through-hole formation against wet etching the glass because wet etching results in significant undercut. ECDM of glass is a rapid, lowcost method that provides a near-vertical profile and is suitable for hole formation. The procedure is performed in $40 \% \mathrm{NaOH}$ solution at room temperature, and the glass is machined using approximately $300 \mu \mathrm{m}$ diameter tungsten cathode and $37 \mathrm{~V}$ bias.

Before performing the bonding of the Si and glass wafers, a thin layer of $\mathrm{Al}$ must be deposited into the glass recess to prevent inadvertent bonding of the valve plate to the glass substrate due to a shallow recess depth and very compliant flexures. Anodic bonding is performed at $400{ }^{\circ} \mathrm{C}$ and $800 \mathrm{~V}$, after which the Al layer on SOI wafer is dissolved. The bonded wafers are then diced and prepared for assembly with the ceramic structure and PZT.

The final step is to attach the PZT stack and ceramic cap by epoxy. The piezoelectric actuation provides enough force to displace the Si against inlet pressures that can reach several atmospheres for some cases. The first prototype valve that was tested in room temperature was assembled using regular Devcon 2-part epoxy. However, Devcon epoxy is rated down to only $-40{ }^{\circ} \mathrm{C}$, so for cryogenic testing, Stycast $2850 \mathrm{FT}$ epoxy is used. The PZT does not need to be bonded to the $\mathrm{Si}$ and was not bonded for cryogenic testing. This may also relieve any stress on flexures caused by large temperature variation. To create a normally open valve, the PZT stack is energized at $100 \mathrm{~V}$ during the assembly process, so that it shortens after assembly as the voltage is reduced during 


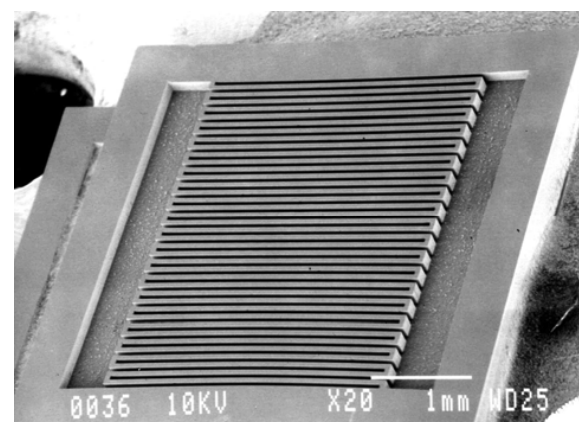

(a)

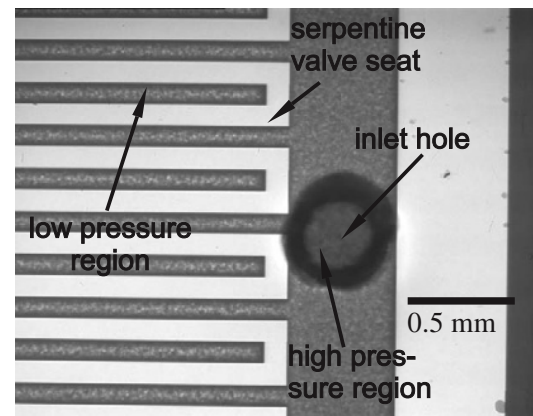

(c)

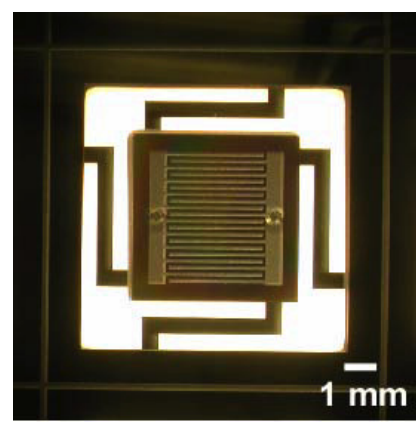

(b)

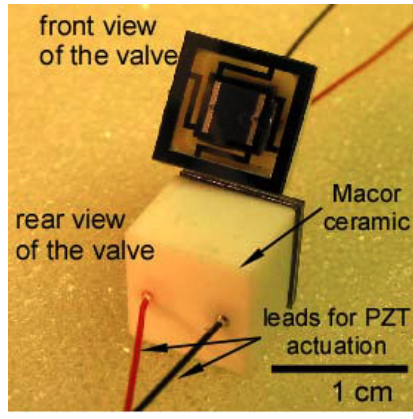

$(d)$

Figure 5. Photographs of the fabricated device. (a) SEM photograph of the silicon valve plate with groove patterns right after the three-step DRIE process. (b) Picture of a die after the anodic bond. (c) Close-up view near the hole with serpentine groove patterns for perimeter augmentation. (d) Completely assembled valve structure. Two valves (front and back) are shown.

operation (figure 4). Note in the figure that the epoxy not only acts as an adhesive layer but also compensates the height difference between the PZT actuator and ceramic housing. The completed valve structure with final dimensions of $1 \times 1 \times$ $1 \mathrm{~cm}^{3}$ is pictured in figure 5 .

\section{Modeling and experimental results}

A flow model was based upon the solution of the NavierStokes equations using computational fluid dynamic (CFD) software applied to the critical valve components. The results of the CFD models were used to generate empirical formulae of these components which could be interfaced in order to predict the flow rate through the valve. First, room temperature tests were conducted to verify the model and establish baseline performance characteristics of the valve at low and high pressures. Next, cryogenic experiments were undertaken to verify operation and determine temperature effects on the device. Lastly, high temperature testing was performed to yield more information on the temperature dependences of the valve.

\subsection{Modeling}

A numerical flow model was developed to predict and then verify experimental results. The model used a combination of reduced Navier-Stokes 2D equations and empirical formulae. The flow through the grooves was simplified by assuming that the fluid is incompressible, laminar, constant viscosity and hydrodynamically fully developed. In this limit, the pressure gradient in the groove is related to the local mass flow rate $(\dot{m})$ according to

$$
\frac{\mathrm{d} p}{\mathrm{~d} x}=-\frac{K \mu \mathrm{per}_{g}^{2}}{32 \rho A_{c, g}^{3}} \dot{m}
$$

where $p$ is the local pressure, $\mu$ and $\rho$ are the viscosity and density of the fluid, respectively, both of which are assumed to be constant. $\operatorname{per}_{g}$ and $A_{c, g}$, respectively, are the perimeter and cross-sectional area of the groove. The parameter $K$ is a constant that depends on the groove aspect ratio. Flow through the land region was assumed to be governed by the continuity equation:

$$
\frac{\partial u_{m}}{\partial x}+\frac{\partial v_{m}}{\partial y}=0
$$

where $u_{m}$ and $v_{m}$ are the averaged (across the height of the land) local $x$ and $y$ velocities through the land. The averaged velocities are related to the pressure gradient according to

$$
u_{m}=-\frac{h^{2}}{12 \mu} \frac{\partial p}{\partial x}, \quad v_{m}=-\frac{h^{2}}{12 \mu} \frac{\partial p}{\partial y}
$$

where $h$ is the valve seat clearance. The above set of equations was discretized in a single land and groove and then solved using sparse matrix decomposition in the Matlab(c) environment. The results of the model were characterized using a set of non-dimensional numbers governing the flow through a single land and groove. A second full valve model was developed based on these non-dimensional relationships and implemented using Engineering Equation Solver (EES) in order to determine the simulated flow rate for a particular 


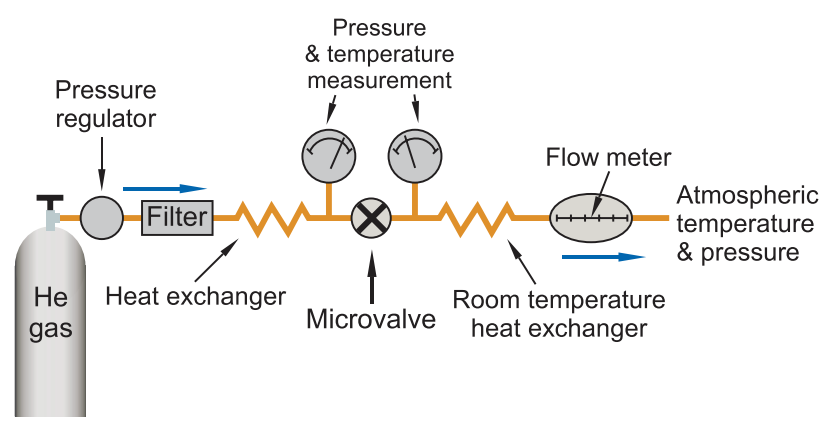

Figure 6. Schematic of the test setup for the He gas flow measurement. Flow rate through the valve is measured while monitoring the inlet and outlet pressures. For low or high temperature testing, heat exchangers are placed to cool or heat the He gas that enters the valve and also bring it back to room temperature as it exits the valve.

valve geometry [31]. More details about the development of the numerical flow model can be found in [32].

The model was obtained by assuming that the hole diameters for inlet and outlet are $350 \mu \mathrm{m}$ and displacement of PZT at $60 \mathrm{~V}$ is $4 \mu \mathrm{m}$. In addition, a linear relationship between PZT displacement and voltage was assumed. Thus, seat clearance from the glass substrate can be expressed as in equation (7):

$$
\text { clearance }(\mu \mathrm{m})=4-\text { voltage }(\mathrm{V}) \times 0.067 \text {. }
$$

\subsection{Experimental results}

Initial tests were performed at room temperature with $\mathrm{He}$ gas flow. Figure 6 is a schematic of the test. An in-line thermoplastic filter is placed upstream of the device to trap any particles or moisture. Pressure gauges are mounted so that inlet and outlet pressures can be monitored. A copper piping (6.35 $\mathrm{mm}$ diameter) is connected to $0.4 \mathrm{~mm}$ holes in glass through an aluminum header. A ball valve is added at the end so that the outlet pressure can be controlled if necessary.

In the first set of tests, the inlet pressure was regulated (21-55 kPa, gage), and the outlet was maintained at atmosphere, while the flow rate was measured over 0-60 V actuation. As shown in figure 7, as actuation voltage increases, the PZT expands, the clearance between the silicon valve seat and glass substrate decreases, and thus, flow rate decreases. With the gauge pressure of $55 \mathrm{kPa}$ at the inlet, flow rate could be modulated from 0 to $980 \mathrm{~mL} \mathrm{~min}^{-1}$. At $60 \mathrm{~V}$, the valve leakage was below the measurement limit $\left(<0.1 \mathrm{~mL} \mathrm{~min}^{-1}\right)$.

In a separate experiment, the valve was tested at a higher inlet pressure of $345 \mathrm{kPa}$ gauge pressure to verify its operation at high pressure, but the pressure difference between the inlet and outlet was kept at $34.5 \mathrm{kPa}$ since that is the anticipated operating condition for the valve. The test setup for this set of experiments is schematically shown in figure 8. A pressure vessel was used to obtain a high absolute pressure while maintaining a relatively low pressure differential across the valve at room temperature. Absolute pressure was measured at the inlet of the valve while the pressure difference across the valve and volumetric flow rates was measured. Multiple
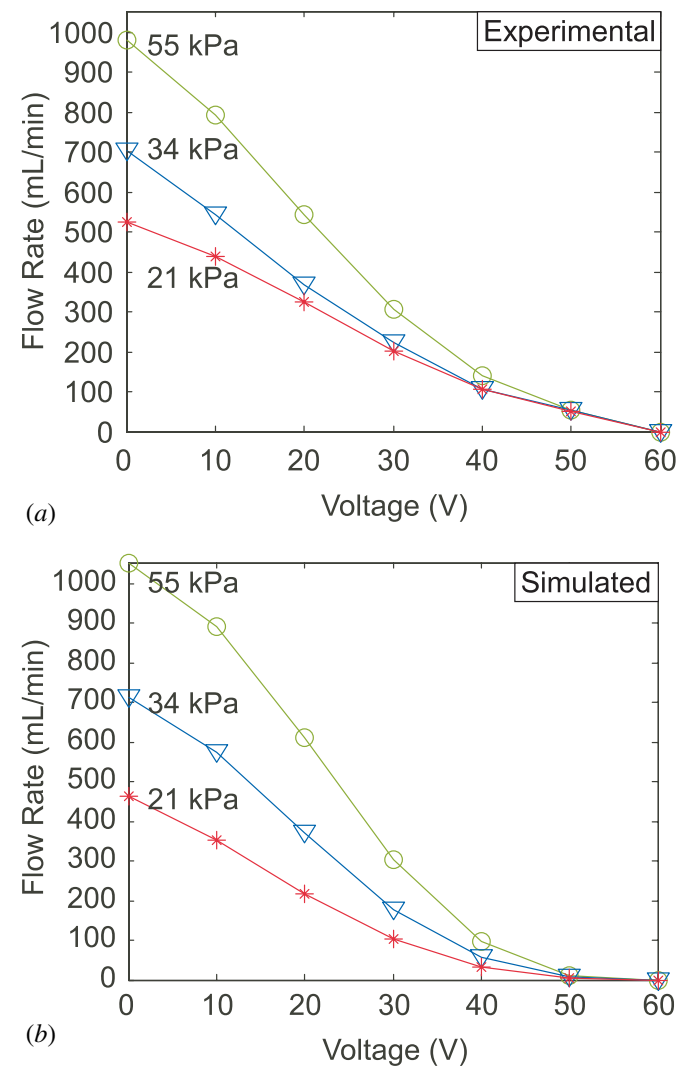

Figure 7. Flow rates as a function of voltage at room temperature from experimental results $(a)$ and analytic model $(b)$. As the actuation voltage increases, the valve is closed and results in a decreased flow rate.

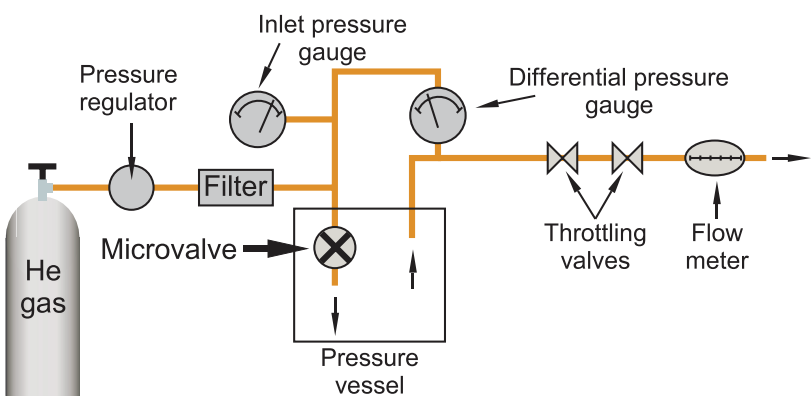

Figure 8. Schematic of the test setup for the high-pressure, room-temperature gas flow measurement. A pressure vessel was used to obtain high pressure while maintaining a relatively low pressure differential across the valve. Throttling valves are used to maintain precise regulation of the pressure differential between the inlet and outlet.

throttling valves were utilized downstream of the valve to allow precise regulation of the pressure difference at high absolute line pressure. Tests were conducted by holding the inlet pressure and differential pressure constants while increasing the valve actuation voltage from 0 to $100 \mathrm{~V}$, and then reducing voltage back to $0 \mathrm{~V}$ in $10 \mathrm{~V}$ increments. The test result comparison with the model prediction is shown in figure 9. The flow rate measurements reveal the hysteretic 


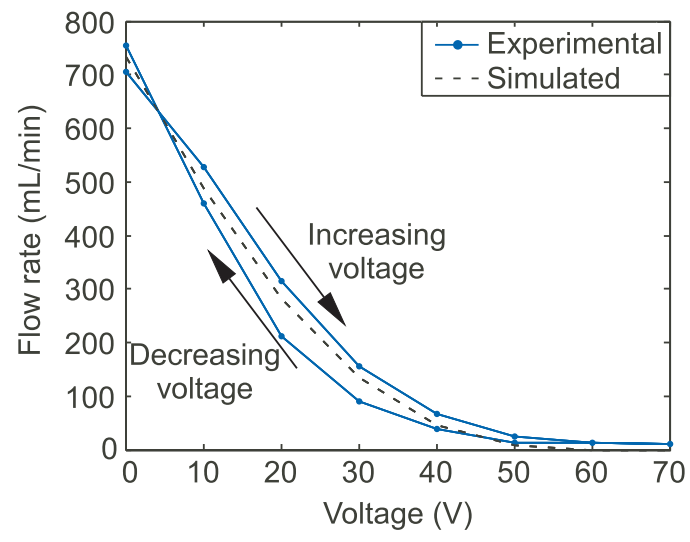

Figure 9. Flow rates as a function of actuation voltage measured at room temperature with an inlet pressure of $345 \mathrm{kPa} \mathrm{G}$ and an inlet to outlet pressure differential of $34 \mathrm{kPa}$. Experimental data are shown with the numerical modeling results. Flow rate measurements show the hysteretic behavior of the PZT actuator.

behavior of the PZT actuator. The model and the experimental results show good agreement.

To verify the operation of the valve at cryogenic temperatures, experiments were performed near liquid nitrogen temperatures $(80 \mathrm{~K})$. (For this valve, Stycast epoxy and a Macor header were used, and the PZT was not bonded to the Si valve plate.) Heat exchangers were added to the test setup as shown in figure 6. The He gas was cooled by passing it through a liquid nitrogen heat exchanger. Inlet and outlet pressures were monitored. In addition, thermocouples were used to probe the inlet and outlet gas temperatures. The gas was then passed through another heat exchanger to bring it back to room temperature and exhausted to the atmosphere while the flow rate was measured.

The valve performance is shown in figure 10 for inlet gauge pressures of $35 \mathrm{kPa}, 70 \mathrm{kPa}$ and $104 \mathrm{kPa}$ with predicted flow rates using the model. Since the piezoelectric coefficient at $80 \mathrm{~K}$ is diminished from its room temperature value, the voltage required to completely stop flow is almost doubled to a value of about $120 \mathrm{~V}$. Reasonable agreement between the experimental data and the model predictions is obtained by assuming an initial valve seat clearance of $1.03 \mu \mathrm{m}$. The reduced valve seat clearance is most likely due to an expansion mismatch between the PZT and Macor enclosure.

The normalized flow rate (NFR) is presented in figure 11. This is defined as

$$
\mathrm{NFR}=\frac{\text { flow rate at corresponding voltage }}{\text { flow rate at } 0 \mathrm{~V}} .
$$

In figure 11, the three curves obtained at different inlet pressures look very similar. This similarity illustrates consistent modulation of the valve over the range of inlet pressures tested.

Although these valves are fabricated to be used for cryogenic applications, they have been tested at elevated temperatures up to $110{ }^{\circ} \mathrm{C}$ to examine their operating temperature range and to explore other possible applications. The experimental setup for the high temperature test was very similar to that of cryogenic temperature, but instead of
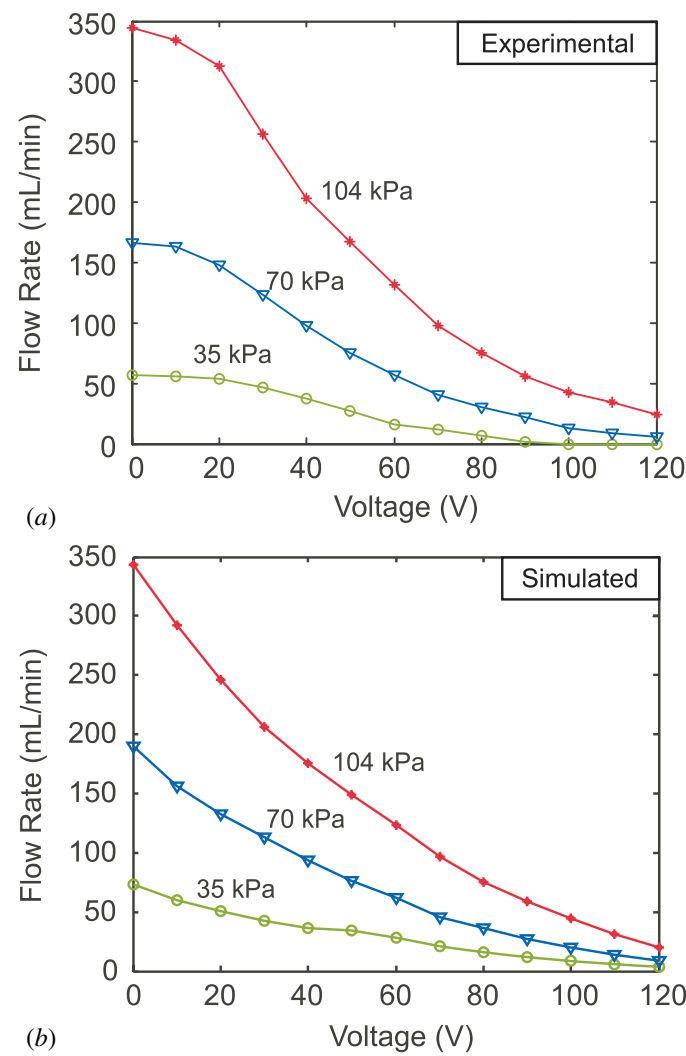

Figure 10. Flow rates as a function of voltage at liquid nitrogen temperature $(80 \mathrm{~K})$ from experimental results $(a)$ and the analytical model $(b)$. The experimental data agree with the model predictions assuming an initial valve seat clearance of $1.03 \mu \mathrm{m}$.

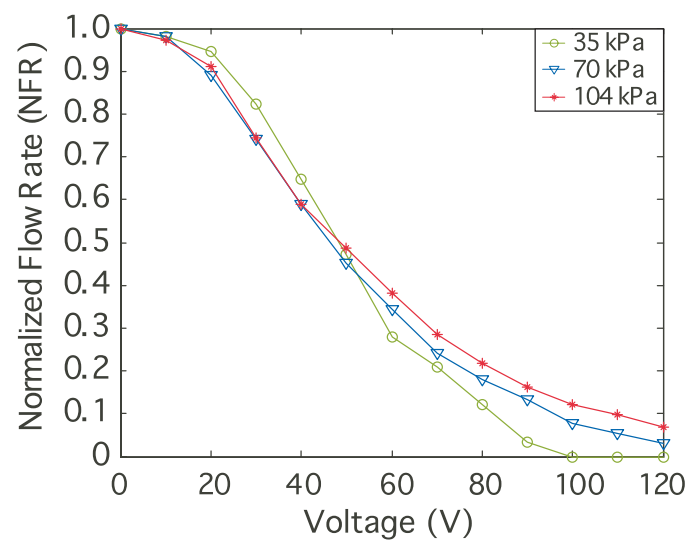

Figure 11. The normalized flow rate as a function of actuation voltage obtained at cryogenic temperature illustrates consistent modulation of the valve over the range of inlet pressures.

exposing the heat exchanger and the valve to liquid nitrogen, they were submerged in a heat bath at $110{ }^{\circ} \mathrm{C}$. To compare the valve's room temperature behavior with that at high temperature, data were collected at both temperatures and plotted in figure 12. In an un-actuated state, the flow rate was higher at elevated temperature and it required a much larger actuation voltage $(170 \mathrm{~V})$ to completely close the valve. This result occurs because the thermal expansion of Macor is 


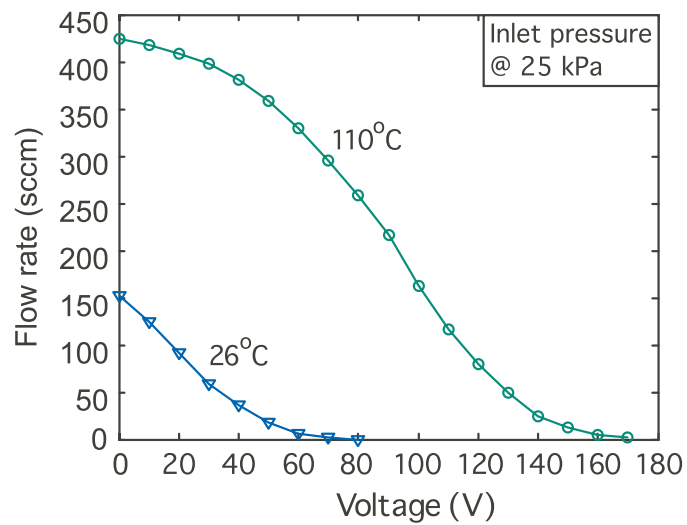

Figure 12. The valve remains operational at temperatures exceeding $100{ }^{\circ} \mathrm{C}$. However, at elevated temperatures, larger valve opening due to thermal expansion mismatch results in larger flow rates and a higher closing voltage.

larger than that of PZT, resulting in a larger separation of the silicon valve plate from glass at zero actuation voltage. To fully close the valve, the PZT needs to travel further, requiring a larger actuation voltage at elevated temperatures compared to room temperature.

The flow rates from the model tend to be slightly larger than the experimental results, but in general, they match reasonably well (figure 7). The main discrepancy comes from uncertainties in seat clearance and inaccurate inlet and outlet hole sizes used in the model. Compressibility of He gas and hysteretic behavior of PZT also contribute to the difference between the model and experimental data.

\subsection{Dynamic characteristics}

A finite element analysis and PSPICE ${ }^{\mathrm{TM}}$ simulation were performed to model the transient behavior of the valve and also analyze its frequency response. Then the model was verified by vibrometer measurement. A Von-Mises stress analysis of silicon and glass die showed that at room temperature stress is mainly present at the bonding interface. A maximum stress of about $21 \mathrm{MPa}$ is calculated at the corners of the bonding rim, and the crab-leg flexures successfully relieve the stress and leave the valve plate and the flexures virtually stress free. Modal analysis showed that the first resonant frequency of the valve plate is at $739 \mathrm{~Hz}$ and subsequent resonant frequency, which is the tilting motion of the valve plate, occurs at $1.3 \mathrm{kHz}$. An equivalent circuit model for the valve was constructed taking account of electrical and mechanical properties of the PZT actuator and Si valve plate. However, it was found that electrical impedance of the PZT actuator is a dominant factor in transient and frequency response of the microvalve. The actuator has relatively large capacitance value $(\approx 700 \mathrm{nF})$, which is a characteristic of a stacked PZT actuator. The PSPICE transient analysis showed approximately $670 \mu \mathrm{s}$ transition time with a $3 \mathrm{~dB}$ bandwidth at $710 \mathrm{~Hz}$.

To accurately measure the dynamic behavior of the valve, a laser Doppler vibrometer (Polytec, Inc., PSV-400 sensor head with OFV-5000 controller) was used. A step input from

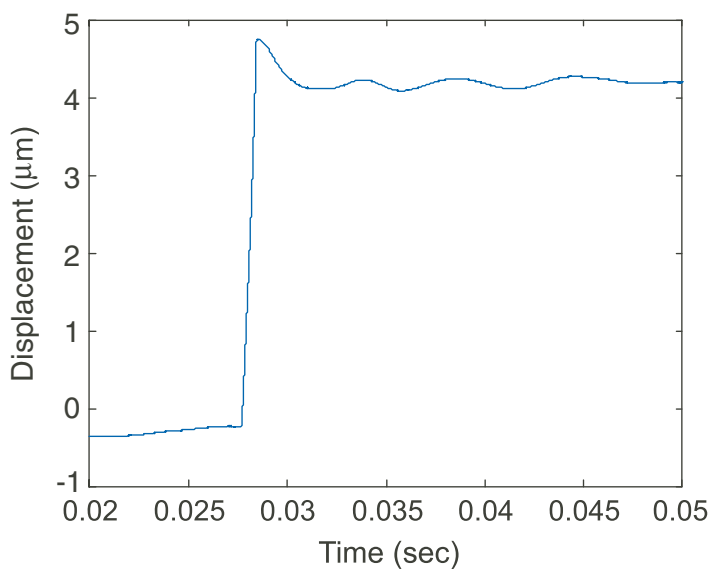

Figure 13. Transient response of the valve measured using a laser Doppler vibrometer with a sampling rate of $1.28 \mathrm{MHz}$. The response time for 0 to $100 \mathrm{~V}$ actuation is measured to be $700 \mu$ s. Some oscillations are evident due to the mechanical properties of PZT.

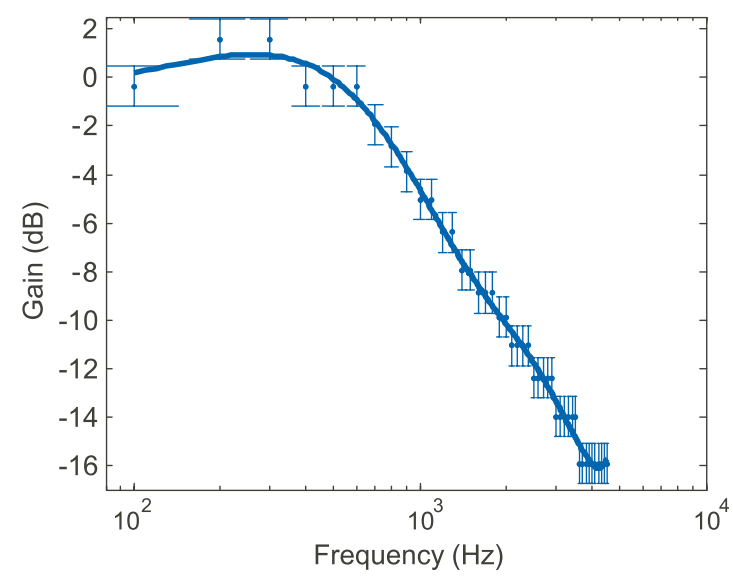

Figure 14. The bandwidth of the valve at room temperature is determined by $100 \mathrm{~V}$ square waves applied from $100 \mathrm{~Hz}$ to $4.5 \mathrm{kHz}$ in $100 \mathrm{~Hz}$ increments. The displacements are measured and normalized to the DC valve. The dots represent data points with error bars. The best fit curve is also plotted. The $3 \mathrm{~dB}$ bandwidth occurs at around $820 \mathrm{~Hz}$.

0-100 V was applied to the actuator while the Si valve seat displacement was measured with a sampling rate of $1.28 \mathrm{MHz}$. The measured results are presented in figure 13. The plot shows the response time of $700 \mu \mathrm{s}$ which is in good agreement with the PSPICE analysis result. The small oscillation is likely due to the mechanical properties of PZT, such as stiffness and damping factor. To find the bandwidth of the valve, the displacements were measured while a 0 to $100 \mathrm{~V}$ square wave was applied from $100 \mathrm{~Hz}$ to $4.5 \mathrm{kHz}$ in $100 \mathrm{~Hz}$ increments. The amplitudes were normalized to the DC value and are plotted in figure 14. The $-3 \mathrm{~dB}$ mark occurs at around $820 \mathrm{~Hz}$ which is also comparable to the simulated value. The bandwidth is limited by the capacitance of the PZT.

At $60 \mathrm{~V}$ steady state actuation, the leakage current through the actuator was measured to be only $2.7 \mathrm{nA}$ which means the valve only consumes $0.16 \mu \mathrm{W}$ of power. Most power consumption occurs during open-to-close transition of the 
valve, and using the measured impedances of the PZT actuator, PSPICE simulation showed the power consumption of $2.3 \mathrm{~mJ}$ per 0 to $60 \mathrm{~V}$ actuation cycle.

\section{Discussion and conclusions}

This effort has resulted in the successful fabrication of a piezoelectrically actuated ceramic-Si-glass microvalve for distributed cooling applications. Piezoelectric actuation provides proportional flow control that generates enough force to withstand high inlet pressures with minimal power consumption. At steady state, the valve only consumes $0.16 \mu \mathrm{W}$ of power. A perimeter augmentation scheme was used to overcome the limited displacement of PZT and provide large flow modulation. The valve was tested across a wide range of temperatures. At room temperature, a flow rate of $980 \mathrm{~mL} \mathrm{~min}{ }^{-1}$ was measured with a inlet pressure of $55 \mathrm{kPaG}$, which is orders of magnitude higher in flow modulation capability than previously reported piezoelectric microvalves [17-20]. The operation of the valve was validated at inlet pressures up to $345 \mathrm{kPa} \mathrm{G}$ while maintaining $34 \mathrm{kPa}$ of pressure differential between inlet and outlet pressures, delivering sufficient flow rate. The performance of the valve was evaluated at wide range of temperatures. At cryogenic temperatures $(80 \mathrm{~K})$, higher voltages $(\approx 120 \mathrm{~V})$ were required to completely close the valve due to the degraded piezoelectric coefficient, and separation between the silicon valve seat and glass plate was decreased as a result of thermal mismatch between the Macor and the PZT actuator. The valve successfully modulated gas flow from $350 \mathrm{~mL} \mathrm{~min}^{-1}$ down to $20 \mathrm{~mL} \mathrm{~min}^{-1}$, at an inlet pressure of $104 \mathrm{kPa}$ higher than the atmosphere, and it showed consistent modulation capability over different values of inlet pressures. The experimental results followed closely with predictions from the numerical model. The operation of the valves was also verified at elevated temperatures. The high actuation voltage required to close the valve at elevated temperatures suggests that a conservative upper limit of operating temperature is somewhat lower than $110^{\circ} \mathrm{C}$. The transient analysis showed $700 \mu$ s response time of the valve and the bandwidth of the device was measured to be $820 \mathrm{~Hz}$.

The valves can scale down further, especially when a high flow rate is not desired, by having a smaller valve plate and a shorter PZT stack. With minor modifications, it can be used for liquid flow modulation in various microfluidic applications [33]. In addition, it can be deployed to operate in harsh environments, due to the ability to work across a wide range of temperatures and ceramic encapsulation.

\section{Acknowledgments}

The authors are grateful to the Michigan Nanofabrication Facility (MNF), and colleagues at the University of Michigan, especially Mr W Zhu for help with equipment. The authors also thank Mr D Hoch at University of Wisconsin for valuable discussions and Mr G Palombo at Polytec for help with vibrometer measurements. This work is supported primarily by NASA under award number NNA05CP85G.

\section{References}

[1] Benford D J, Amato M J, Mather J C, Moseley S H Jr and Leisawitz D T 2004 Mission concept for the single aperture far-infrared (SAFIR) observatory Astrophys. Space Sci. 294 177-212

[2] Hastings L J, Plachta D W, Salerno L and Kittel P 2001 An overview of NASA efforts on zero boiloff storage of cryogenic propellants Cryogenics $\mathbf{4 1} 833-9$

[3] Terry S C, Jerman J H and Angell J B 1979 A gas chromatographic air analyzer fabricated on a silicon wafer IEEE Trans. Electron Dev. ED-26 1880-6

[4] Ikehara T, Yamagishi H and Ikeda K 1997 Electromagnetically driven silicon microvalve for large-flow pneumatic Controls Proc. SPIE-The Int. Soc. Opt. Eng. 3242 136-44

[5] Shinozawa Y, Abe T and Kondo T 1997 A proportional microvalve using a bi-stable magnetic actuator IEEE Int. Workshop on Micro Electro Mechanical Systems (MEMS '97) (Nagoya, Japan, January 1997) pp 233-7

[6] Fu C, Rummler Z and Schomburg W 2003 Magnetically driven micro ball valves fabricated by multilayer adhesive film bonding J. Micromech. Microeng. 13 S96-102

[7] Dubois P, Guldimann B and de Rooij N F 2001 High-speed electrostatic gas microvalve switching behavior Proc. SPIE-The Int. Soc. Opt. Eng. $4560217-26$

[8] Collier J, Wroblewski D and Bifano T 2004 Development of a rapid-response flow-control system using MEMS microvalve arrays J. Microelectromech. Syst. 13 912-22

[9] Vandelli N, Wroblewski D, Velonis M and Bifano T 1998 Development of a MEMS microvalve array for fluid flow control J. Microelectromech. Syst. 7 395-403

[10] Huff M A, Gilbert J R and Schmidt M A 1993 Flow characteristics of a pressure-balanced microvalve IEEE Int. Conf. Solid-State Sensors and Actuators (Transducers '93) (Yokohama, Japan, June 1993) pp 98-101

[11] Zdeblick M J and Angell J B 1987 A microminiature electric-to-fluidic valve IEEE Int. Conf. Solid-State Sensors and Actuators (Transducers '87) (Chicago, June 1987) pp 437-9

[12] Rich C A and Wise K D 2003 A high-flow thermopneumatic microvalve with improved efficiency and integrated state sensing IEEE/ASME J. Microelectromech. Syst. 12 201-8

[13] Barth P W, Beatty C C, Field L A, Baker J W and Gordon G B 1994 A robust normally-closed silicon microvalve Solid-State Sensor and Actuator Workshop (Hilton Head '94) (Hilton Head Island, South Carolina, June 1994) pp 248-50

[14] Barth P W and Gordon G 1994 High performance micromachined valve orifice and seat US Patent $\# 5,333,831$

[15] Messner S, Muller M, Burger V, Schaible J, Sandmaier H and Zengerle R 1998 A normally-closed, bimetallically actuated 3-way microvalve for pneumatic applications IEEE Int. Workshop on Micro Electro Mechanical Systems (MEMS '98) (Heidelberg, Germany, January 1998) pp 40-4

[16] Kohl M, Dittmann D, Quandt E and Winzek B 2000 Thin film shape memory microvalves with adjustable operation temperature Sensors Actuators A 83 214-9

[17] Esashi M 1990 Integrated micro flow control systems Sensors Actuators A 21 161-7

[18] Esashi M, Shoji S and Nakano A 1989 Normally closed microvalve and micropump fabricated on a silicon wafer Sensors Actuators 20 163-9

[19] Shoji S, Schoot B, Rooij N and Esashi M 1991 Smallest dead volume microvalves for integrated chemical analyzing systems IEEE Int. Conf. on Solid-State Sensors and Actuators (Transducers '91) (San Francisco, June 1991) pp 1052-5

[20] Yang E H, Lee C, Mueller J and George T 2004 Leak-tight piezoelectric microvalve for high-pressure gas 
micropropulsion IEEE J. Microelectromech. Syst. $13799-807$

[21] Chakraborty I, Tang W C, Bame D P and Tang T K 2000 MEMS micro-valve for space application Sensors Actuators A 83 188-93

[22] Roberts D C, Hanqing L, Steyn J L, Yaglioglu O, Spearing S M, Schmidt M A and Hagood N W 2003 A piezoelectric microvalve for compact high-frequency, high-differential pressure hydraulic micropumping systems IEEE J. Microelectromech. Syst. 12 81-92

[23] Rogge T, Rummler Z and Schomburg W K 2004 Polymer micro valve with a hydraulic piezo-drive fabricated by the AMANDA process Sensors Actuators A $110206-12$

[24] Park J M, Taylor R P, Evans A T, Brosten T R, Nellis G F, Klein S A, Feller J R, Salerno L and Gianchandani Y B 2006 A piezoelectrically actuated ceramic-Si-glass microvalve for distributed cooling systems Solid-State Sensor and Actuator Workshop (Hilton Head '06) (Hilton Head Island, South Carolina, June 2006) pp 248-51

[25] Gerson R 1962 Piezoelectric and dielectric properties of lead titanate zirconate ceramics at low temperatures $J$. Appl. Phys. 33 830-2

[26] Taylor R P, Nellis G F, Klein S A, Hoch D W, Feller J, Roach P, Park J M and Gianchandani Y 2005 Measurements of the material properties of a laminated piezoelectric stack at cryogenic temperatures 30th Int. Cryogenic Materials Conf. (Keystone, Colorado, Aug. 29-Sept. 2 2005) pp 200-7
[27] Taylor R P 2005 A micromachined croyogenic valve for distributed cooling applications MS Thesis The University of Wisconsin, Madison

[28] Andersen B A M, Hansen O and Kristensen M 1997 Spatial variation of the etch rate for deep etching of silicon by reactive ion etching J. Vac. Sci. Technol. B 15 993-9

[29] Taylor H K, Sun H, Hill T F, Farahanchi A and Boning D S 2006 Characterizing and predicting spatial nonuniformity in the deep reactive ion etching of silicon J. Electrochem. Soc. 153 C575-85

[30] Fascio V, Wuthrich R, Viquerat D and Langen H 1999 3D microstructuring of glass using electrochemical discharge machining (ECDM) Int. Symp. Micromechatronics and Human Science (Nagoya, Japan, Nov. 1999) pp 179-83

[31] Klein S A 2002 Engineering Equation Solver, The University of Wisconsin-Madison http://sel.me.wisc.edu/ees/new_ees.html

[32] Brosten T R, Park J M, Evans A T, Rasmussen K, Nellis G F, Klein S A, Feller J R, Salerno L and Gianchandani Y B 2007 A numerical flow model and experimental results of a cryogenic microvalve for distributed cooling applications Cryogenics 47 501-9

[33] Evans A, Park J M, Taylor R P, Brosten T R, Nellis G F, Klein S A, Feller J R, Salerno L and Gianchandani Y B 2006 A low power, micromachined proportional valve for drug delivery Int. Conf. Miniaturized Chemical and Biochemical Analysis Systems (MicroTAS 2006) (Tokyo, Japan, Nov. 2006) pp 1148-50 